\title{
Preparation and recording characteristics of rigid disks using Co-Zn ferrite sputtered films for high density magnetic recording with perpendicular anisotropy
}

\author{
K. NOMA, N. MATSUSHITA, S. NAKAGAWA and M. NAOE \\ Dept. of Physical Electronics, Tokyo Institute of Technology, \\ 2-12-1 O-okayama, Meguro, Tokyo 152, JAPAN
}

\begin{abstract}
The improved magnetic recording system with higher potential were proposed to surpass the conventional systems in recording density. In isotropic recording system, the recording magnetization were arranged obliquely to the film plane. Because of large magnetocrystalline anisotropy, the stability of the recorded magnetization and sharpness of reproducing field were expected to be almost same as perpendicular recording system. In this study, Co-Zn ferrite films prepared by Facing Targets Sputtering (FTS) method at relatively low substrate temperature were used for isotropic media using conventional ring head. The higher recording density such as $\mathrm{D}_{50}$ of $31 \mathrm{kfrpi}$ were obtained.
\end{abstract}

\section{INTRODUCTION}

The spinel type of Co ferrite was expected to be applicable for high density magnetic recording media because of their high coercivity, corrosion resistivity and hardness. Since the easy axes of well (111) oriented Co ferrite films are distributed as corn-like shape, the films can be regarded as isotropic media for high densty recording[1]. It had been clarified that Co ferrite films deposited on $\mathrm{ZnO}$ underlayer by Facing Targets Sputtering (FTS) method were composed of crystallites

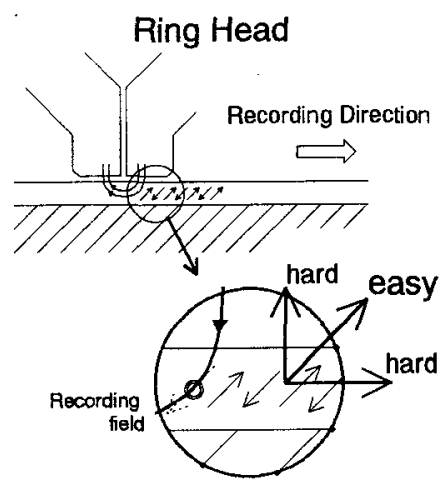

Fig. 1 Schematic images of principles of isotropic recording system. with well (111) orientation[2,3]. However, these Co ferrite/ZnO bilayer films possessed too high coercivity $\mathrm{H}_{\mathrm{c}}$ above $3 \mathrm{kOe}$ and not so large magnetization $4 \pi \mathrm{M}_{\mathrm{s}}$. In addition, the surface roughness of the films prepared at substrate temperature $T_{s}$ above $400{ }^{\circ} \mathrm{C}$ were so large that they were not suitable for recording media with low head flying-height[2].

Zn substituted Co ferrite (Co-Zn ferrite) films possess well (111) orientation and lower $H_{c}$ because of the ordered crystallite growth due to the site preference of $\mathrm{Zn}$ atoms to tetragonal sites in spinel structure and the reduction of the large magnetic anisotropy originated from Co ions[4].

In this paper, the dependences of the crystallographic and magnetic properties on the $\mathrm{Zn}$ content were studied. The Read/Write characteristics of 2-inch Co-Zn ferrite thin film hard disks were also investigated.

\section{EXPERIMENTAL}

All Co-Zn ferrite films were prepared by FTS method[5]. Sintered Co-Zn ferrite plates with different compositions were used as sputtering tar- 
gets. The composition of the targets were controlled by adjusting the ratio of starting materials. Specimen films were prepared on thermally oxidized silicon wafers at the substrate temperature $\mathrm{T}_{\mathrm{s}}$ in the range from $100^{\circ} \mathrm{C}$ (without heating substrate) to $500^{\circ} \mathrm{C}$. The crystallographic characteristics were analyzed by X-ray diffraction method, and the magnetic properties such as $4 \pi \mathrm{M}_{\mathrm{s}}$ and $\mathrm{H}_{\mathrm{c}}$ were evaluated by VSM.

\section{RESUlts AND DISCUSSION}

\section{A. Crystallographic and Magnetic Characteris-} tics

Fig. 2 shows the $\mathrm{X}$-ray diffraction patterns of Co-Zn ferrite films prepared at various $\mathrm{T}_{\mathrm{s}}$ using the targets with the composition of $\mathrm{Co}_{0.5} \mathrm{Zn}_{0.46} \mathrm{Fe}_{2.04} \mathrm{O}_{y}$. It was observed that only spinel (222) diffraction peak was appeared at low $\mathrm{T}_{\mathrm{s}}$ of $100{ }^{\circ} \mathrm{C}$. However, spinel (311) peak intensity increased, while (222) peak intensity decreased at higher $\mathrm{T}_{\mathrm{s}}$. Finally, at $\mathrm{T}_{\mathrm{s}}$ above $400^{\circ} \mathrm{C}$, Co-Zn ferrite films were composed of only crystallites with (311) orientation.

The surface morphorogy of the films were esti-

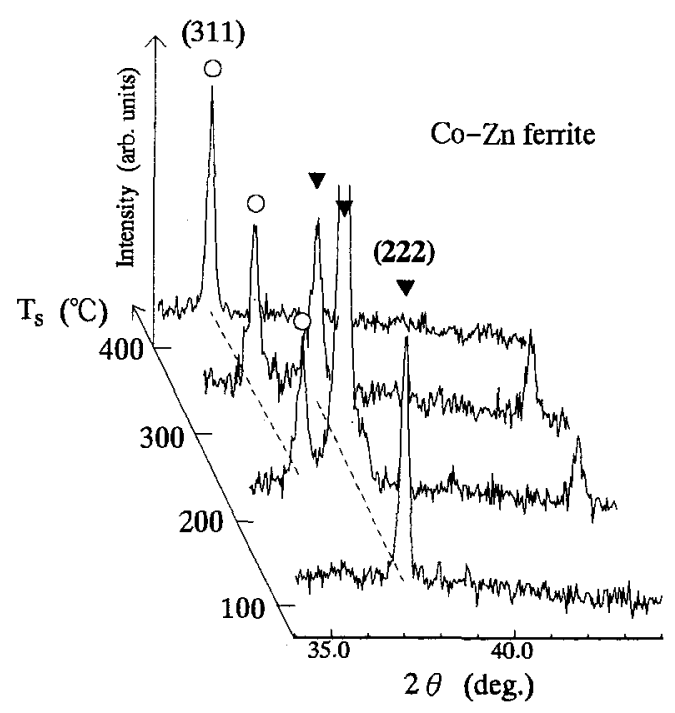

Fig. 2 XRD patterns at various $\mathrm{T}_{\mathrm{s}}$ of $100 \sim$ $400^{\circ} \mathrm{C}$.

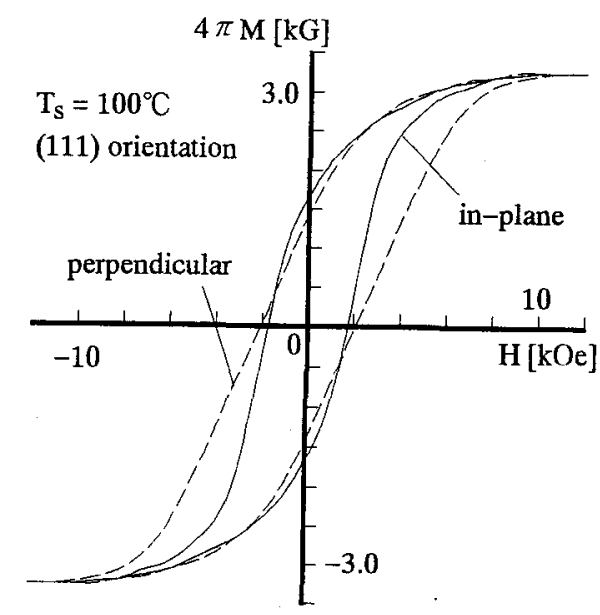

Fig. 3 Typical hysteresis loop of (111) orientated films.

mated by using atomic force microscopy and the center-line average roughness $R_{a}$ and the rootmean-square roughness $R_{r m s}$ of the film prepared at $\mathrm{T}_{\mathrm{s}}$ of $100^{\circ} \mathrm{C}$ were 1.42 and $1.73 \mathrm{~nm}$, and those of the film prepared at $\mathrm{T}_{\mathrm{s}}$ of $400{ }^{\circ} \mathrm{C}$ were 94.9 and $116.8 \mathrm{~nm}$, respectively[5].

The value of $4 \pi \mathrm{M}_{\mathrm{s}}$ of the films prepared at $\mathrm{T}_{\mathrm{s}}$ of $100{ }^{\circ} \mathrm{C}$ with (111) orientation were 260 $\mathrm{emu} / \mathrm{cm}^{3}(3.3 \mathrm{kG})$ and the maximum value of 380 $\mathrm{emu} / \mathrm{cm}^{3}(4.8 \mathrm{kG})$ were obtained in the film prepared at $\mathrm{T}_{\mathrm{s}}$ of $250{ }^{\circ} \mathrm{C}$ where a large (222) peak and the minimum $\Delta \theta_{50(111)}$ value of $2.8^{\circ}$ were observed by XRD analysis.

The in-plane and perpendicular coercivity $\mathrm{H}_{\mathrm{c}}$ were almost the same value of $1.5 \sim 2.0 \mathrm{kOe}$ over all range of $\mathrm{T}_{\mathbf{s}}[5]$. The shape of the hysteresis loop was isotropic for highly (111) oriented film as shown in Fig. 3.

\section{B. Dependences on $Z n$ Content}

The specimen films were deposited by using three types of targets. The composition of the targets are listed in Table 1. In Fig. 4, the quality factor for $(111)$ orientation $f_{c(111)}$ were evaluated from following equation:

$$
f_{c(111)}=\frac{p-p_{0}}{1-p_{0}}, \quad p=\frac{\Sigma I(111)}{\Sigma I(h k l)}, \quad p_{0}=\frac{\Sigma I_{0}(111)}{\Sigma I_{0}(h k l)}
$$

where $I(h k l)$ is the peak intensity of (hkl) refrec- 


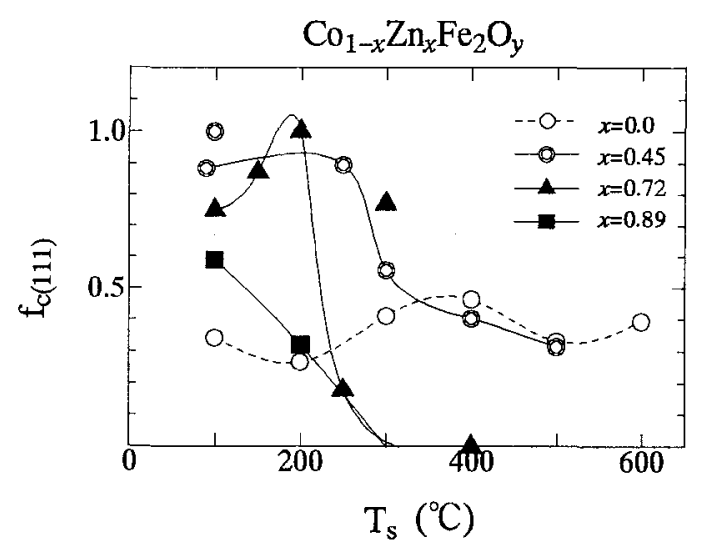

Fig. 4 Dependences of $f_{c(111)}$ on $T_{s}$ for each target composition.

Table 1 Composition of targets analyzed by ICPS (content of metallic ion is normalized for $\left.\mathrm{C}_{\mathrm{Zn}}+\mathrm{C}_{\mathrm{Co}}+\mathrm{C}_{\mathrm{Fe}}=3.0\right)$.

\begin{tabular}{l|rrr}
\hline & $\mathrm{C}_{\mathrm{Zn}}$ & $\mathrm{C}_{\mathrm{Co}}$ & $\mathrm{C}_{\mathrm{Fe}}$ \\
\hline target-A $(x=0.3)$ & 0.313 & 0.655 & 2.031 \\
target-B $(x=0.7)$ & 0.722 & 0.543 & 1.735 \\
target-C $(x=0.9)$ & 0.894 & 0.207 & 1.899 \\
\hline
\end{tabular}

tion and $I_{0}$ is taken from the reference of JCPDS cards. The crystal orientations were drastically changed by $T_{s}$ for each target composition, and the appropriate $T_{s}$ to attain well (111) orientation in the films were different for each composition.

It has to be noted that $\mathbf{H}_{c}$ of the films were controllable by changing Zn content $x$, and they had a little dependence on $\mathrm{T}_{\mathrm{s}}$ for each composition as shown in Fig. 5. Therefore, Co-Zn ferrite films with prefarable characteristics such as well (111) orientation and moderate $\mathrm{H}_{c}$ about $1.5 \sim$ $2.0 \mathrm{kOe}$ can be obtained by optimizing the target composition and sputtering conditions, especially such as $T_{\mathbf{s}}$.

\section{Read/Write Characteristics}

The specimens for measuring $\mathrm{R} / \mathrm{W}$ characteristics were prepared on thermally oxidized 2-inch silicon wafer at $\mathrm{T}_{\mathrm{s}}$ of 200 and $400{ }^{\circ} \mathrm{C}$ by using

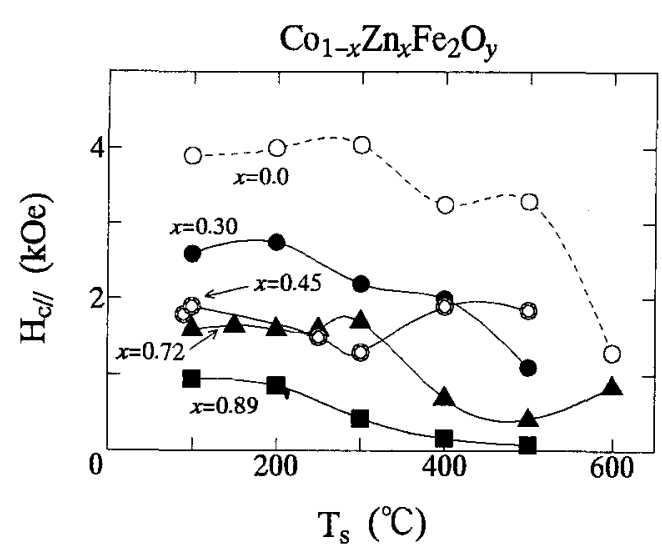

Fig. 5 Dependences of $H_{c}$ on $T_{s}$ for each target composition.

the $\mathrm{Co}_{0.5} \mathrm{Zn}_{0.46} \mathrm{Fe}_{2.04} \mathrm{O}_{y}$ targets. The thickness of the films were around $200 \sim 300 \mathrm{~nm}$. The crystallographic orientations of them were (111) at $\mathrm{T}_{\mathrm{s}}$ of $200^{\circ} \mathrm{C}$ and $(311)$ at $\mathrm{T}_{\mathrm{s}}$ of $400{ }^{\circ} \mathrm{C}$, respectively. Typical values of $4 \pi \mathrm{M}_{\mathrm{s}}$ and $\mathrm{H}_{\mathrm{c}}$ of these films were shown in Table 2.

The $\mathrm{R} / \mathrm{W}$ characteristics of the disks were measured by contact recording system using thin film head with $\mathrm{Co}-\mathrm{Zr}-\mathrm{Nb}$ amorphous core with the gap length of $0.35 \mu \mathrm{m}$. The revolution velocity of the disks were set at 1,200 r.p.m and then the relative velocity was $2.51 \mathrm{~m} / \mathrm{sec}$.

The reproducing signals seemed to be dipulselike and the dipulse ratio at 385 frpi were about 0.4 for the disk with (111) orientation (disk-1) and 0.1 for the disk with (311) orientation (disk2 ), respectively. The output waveform at the recording density of 385 fpi for disk- 1 is shown in Fig. 6. These results suggest that the recorded magnetization in these disks contain perpendicular component of magnetization. The linear

Table 2 Magnetic and other properties of $\mathrm{Co}-\mathrm{Zn}$ ferrite hard disks

\begin{tabular}{l|ccccc}
\hline & $\begin{array}{c}\mathrm{T}_{\mathrm{s}} \\
{\left[{ }^{\circ} \mathrm{C}\right]}\end{array}$ & $\begin{array}{c}\text { orien- } \\
\text { tation }\end{array}$ & $\begin{array}{c}4 \pi \mathrm{M}_{\mathrm{s}} \\
{[\mathrm{kG}]}\end{array}$ & $\begin{array}{c}\mathrm{H}_{\mathrm{c}} \\
{[\mathrm{kOe}]}\end{array}$ & $\begin{array}{c}\text { thickness } \\
{[\mathrm{nm}]}\end{array}$ \\
\hline disk-1 & 200 & $(111)$ & 3.9 & 1.8 & 230 \\
disk-2 & 400 & $(311)$ & 4.4 & 1.2 & 280 \\
\hline
\end{tabular}




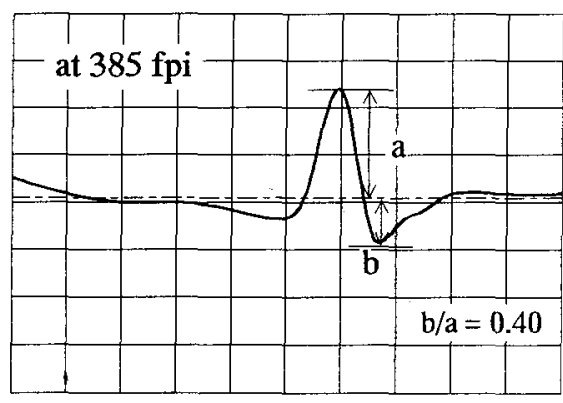

Fig. 6 Output waveform of isolated pulse.

recording density charateristics for both disks are shown in Fig. 7. The amplitude of reproducing signals for disk-1 was smaller than that for disk-2. It was because that the remanent magnetization $M_{r}$ of (311) oriented films were larger than that of (111) film.

But the recording density $D_{50}$ for disk-1 was larger than that for disk-2. One of the reason is that $\mathrm{H}_{\mathrm{c}}$ of the (111) oriented film was higher than that of (311) film. However, since the dipulse ratio for disk-1 was larger than that for disk-2, the recording mode of disk- 2 seemed to be the inplane one and that of disk- 1 was the isotropic one.

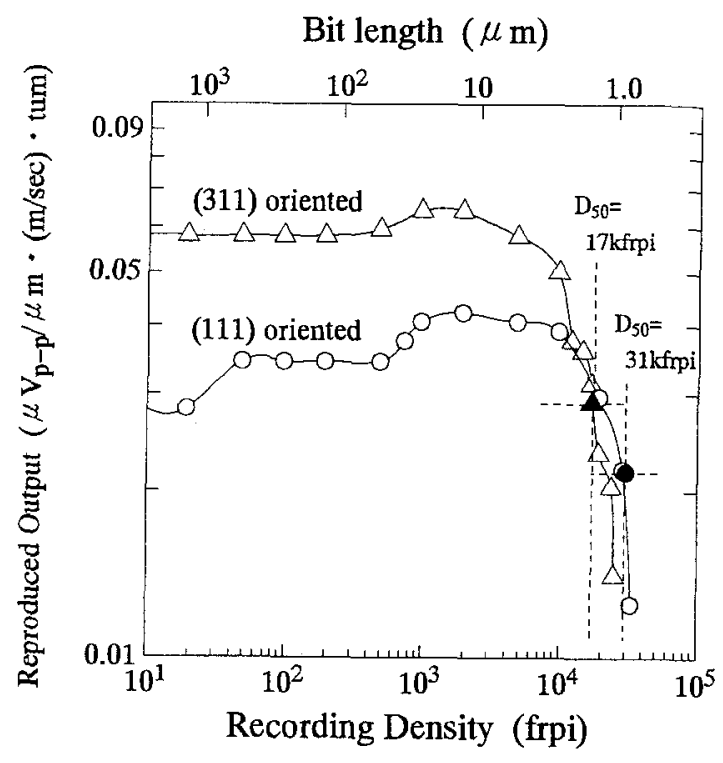

Fig. 7 Read/Write Characteristics on linear recording density.

\section{CONCLUSION}

Co-Zn ferrite films for isotropic recording media were investigated by using FTS method. It was clarified that for each target composition, there was the optimized $\mathrm{T}_{\mathrm{s}}$ for obtaining the films with well (111) orientation and by changing the $\mathrm{Zn}$ content, $\mathrm{H}_{\mathrm{c}}$ of Co-Zn ferrite films were controllable.

By comparing $\mathrm{R} / \mathrm{W}$ characteristics of the disk with (111) orientation and (311) orientation, the former disk seemed to be recorded in isotropic recording mode and have higher potential to improve magnetic recording density. In this study, the linear recording density $D_{50}$ of $31 \mathrm{kfrpi}$ was obtained.

\section{REFERENCES}

[1] J. U. Lemke: IEEE Trans. on Magn., MAG-15 p.1561 (1979)

[2] N. Matsushita, S. Nakagawa and M. Naoe: IEEE Trans. on Magn., MAG-28 p.3108 (1992)

[3] N. Matsushita, K. Noma, S. Nakagawa and M. Naoe: Proc. of the 6th Conference on Ferrites, p.428 (1992)

[4] R. M. Bozorth, E. F. Tilden and A. J. Williams: Phys. Rev. 99 p.1788 (1955)

[5] N. Matsushita, K. Noma, S. Nakagawa and M. Naoe: Proc. of 1st Interinational Conference on Processing Materials for Properties, p.1169 (1993).

[6] N. Matsushita, K. Noma, S. Nakagawa and M. Naoe: J. of Appl. Phys., 75 p.5975 (1994)

[7] S. Iwasaki: IEEE Trans. on Magn., MAG21 p. $71(1985)$ 